\title{
Analysis of ionospheric plasma perturbations before Wenchuan earthquake
}

\author{
X. Zhang, X. Shen, J. Liu, X. Ouyang, J. Qian, and S. Zhao \\ Institute of Earthquake Science, China Earthquake Administration, China \\ Received: 3 March 2009 - Revised: 25 June 2009 - Accepted: 26 June 2009 - Published: 28 July 2009
}

\begin{abstract}
Based on data recorded by the French DEMETER satellite, plasma perturbations have been analyzed before the Wenchuan 8.0 earthquake which occurred on 12 May 2008. Using the revisited orbits, the seasonal variations of the $\mathrm{O}^{+}$density at daytime and nighttime were obtained respectively. There mainly exist two kinds of shapes of $\mathrm{O}^{+}$ density, with peak values in the Northern Hemisphere during May to September and reversely in the Southern Hemisphere during other months. Analysis on local daytime $\mathrm{O}^{+}$ density showed that it reached its lowest values 3 days prior to the earthquake, i.e. on 9 May. With studies in more than 3 month time series and comparison with those in 2006 and 2007, it was found that the significant decrease of the $\mathrm{O}^{+}$ density on 9 May 2008 was different from the trend variations of 2007 and 2006 both with relatively higher $\mathrm{O}^{+}$density in May. In addition, the ion density and temperature was also analyzed before the earthquake at local nighttime. They showed smallest value in $\mathrm{O}^{+}$density and fast and short-term variations in ion temperature on 9 May above the epicenter area. All these plasma anomalies may be related to the Wenchuan earthquake. Finally, using our results and those published in other papers, the possible mechanisms of these ionospheric anomalies were discussed.
\end{abstract}

\section{Introduction}

The DEMETER (Detection of Electro-Magnetic Emissions Transmitted from Earthquake Regions) satellite was launched on 29 June 2004 (Cussac et al., 2006), with an inclination of $98^{\circ}$, and an altitude of $770 \mathrm{~km}$ (change to $660 \mathrm{~km}$ at the end of 2005). The scientific payload on this microsatellite is made of five instruments (Lagoutte et al, 2006): ICE for the

Correspondence to: $\mathrm{X}$. Zhang

(zhangxm69@yahoo.cn) measurement of the electric field, IMSC for the measurement of the magnetic field, IAP a plasma analyzer, IDP a particle detector, and ISL, a set of two Langmuir probes. In primary studies, many anomalous phenomena have been recorded by the DEMETER satellite (Parrot et al., 2006; Sarkar et al., 2007; Bhattacharya et al., 2007), which illustrated that strong earthquakes could induce ionospheric perturbations. The Wenchuan 8.0 earthquake, located at $30.97^{\circ} \mathrm{N}, 103.57^{\circ} \mathrm{E}$, took place on 12 May 2008, and, in this paper, we used the DEMETER data to search for a precursor of this earthquake in the ionosphere.

As to the analysis of plasma parameters, Bošková et al. $(1993,1994)$ has studied the ion composition recorded on Intercosmos-24 (altitude between 2300 and $2500 \mathrm{~km}$ ) before an Iranian earthquake occurring on 20 June 1990. They found increased concentration of the light ions $\mathrm{H}^{+}$and $\mathrm{He}^{+}$ on satellite passes close to the epicenter. Similar studies but at lower altitudes were made by Pulinets et al. (2003) using the AE-C satellite mass spectrometer data. Their results showed a decrease of the mean ion mass when the satellite passed over the epicenter area. Using DEMETER, Parrot et al. (2006) exhibited increase of the density of $\mathrm{H}^{+}$and $\mathrm{He}^{+}$ before two earthquakes in Japan. Before the Pu'er earthquake on 3 June 2007 in China, some perturbations of electron and ion densities have been found by Zhu et al. (2008) on the orbits at a distance up to $1888 \mathrm{~km}$ from the epicenter. As for the Wenchuan earthquake, anomalous phenomena have been studied, such as the decrease of Signal to Noise Ratio (SNR) recorded by DEMETER from 4 VLF transmitters at ground one month before the Wenchuan earthquake, ELF electric field and other plasma perturbations observed on some orbits in 7 days prior to it (He et al., 2009; Zeng et al., 2009). In view of these past results, the ion composition and density recorded by IAP on the DEMETER satellite was analyzed before the Wenchuan M8.0 earthquake.

Published by Copernicus Publications on behalf of the European Geosciences Union. 

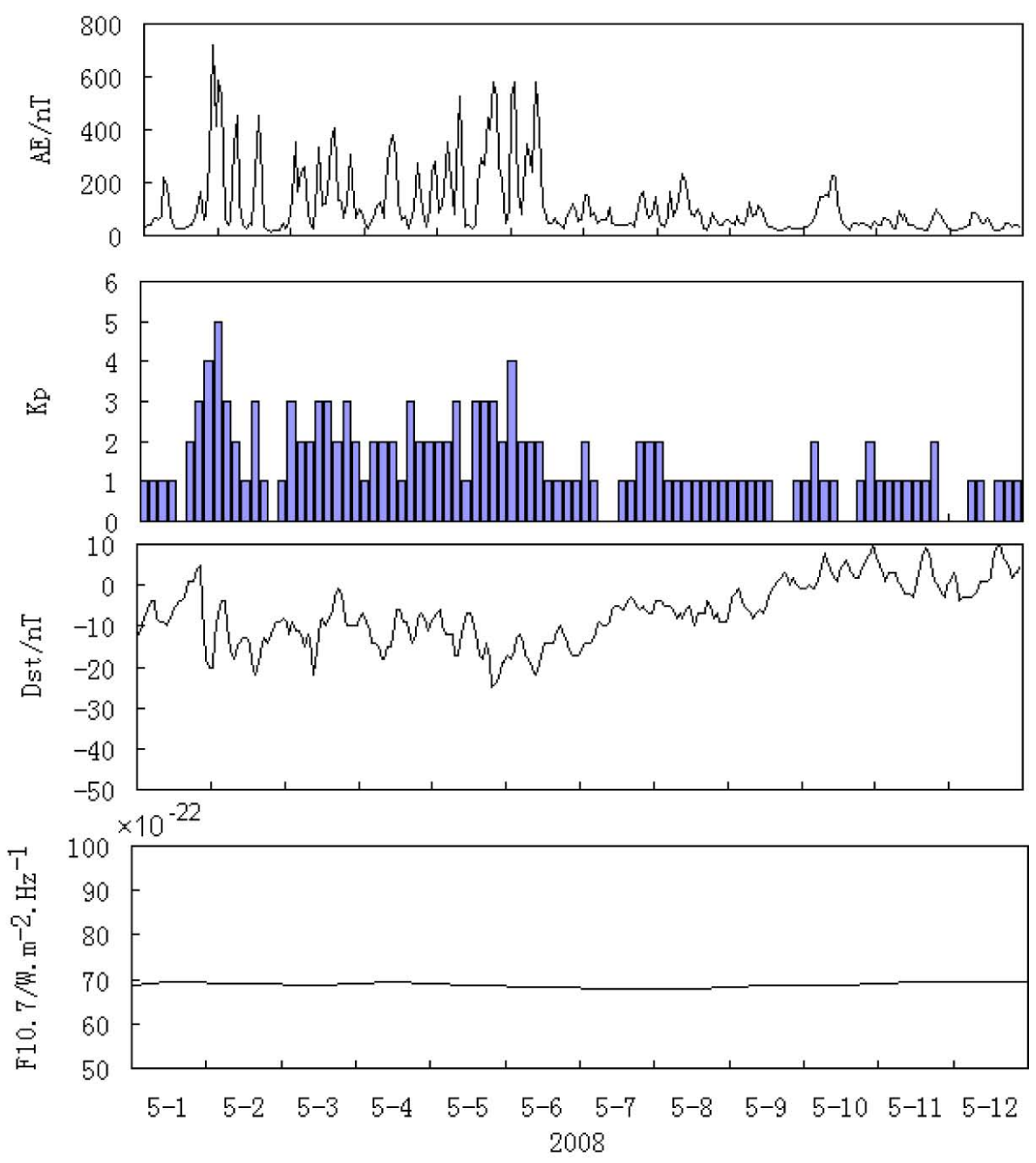

Fig. 1. Geomagnetic index during 1 to 12 of May, 2008.

\section{Geomagnetic condition and data cleaning}

Due to the strong effects of solar and geomagnetic activities on the ionosphere, geomagnetic conditions should be taken account, and the Fig. 1 shows a few indexes such as $A E, k_{p}$, $D_{s t}$ and $F_{10.7}$ from the 1 st to the 12th of May 2008. These plots indicate that, from the 2nd to the 6th, the $A E$ index was relatively high, the $k_{p}$ exceeded 5 , and the $D_{s t}$ was around $-20 \mathrm{nT}$. These indexes all illustrate a more or less continuous moderate geomagnetic activity appearing during this time interval. After 6 May, every index was lower $\left(k_{p}\right.$ varying lower than 2 and $D_{s t}$ not exceeding $-10 \mathrm{nT}$ ), so the geomagnetic condition became quiet then.

The thermal ion spectrometer, IAP, measures the ion density, composition, temperature, and flow velocity. At $660 \mathrm{~km}$ in space, the gas ionization becomes intensive due to the solar emission. At the top of the $\mathrm{F}$ layer, the main ion is $\mathrm{O}^{+}$, while it is $\mathrm{H}^{+}$above $1000 \mathrm{~km}$. The averaged altitude of DEMETER being $660 \mathrm{~km}, \mathrm{O}^{+}$is the main constituent among the three ions $\left(\mathrm{H}^{+}, \mathrm{He}^{+}, \mathrm{O}^{+}\right)$. The densities of $\mathrm{H}^{+}$and $\mathrm{He}^{+}$ are just about one seventh and one tenth of $\mathrm{O}^{+}$, respectively. The $\mathrm{O}^{+}$density detected by IAP was mainly analyzed in this paper.

\section{Analysis on ion density of oxygen}

\subsection{Normal variation shapes of oxygen density}

The DEMETER satellite has a revisited period of 16 days, so it is convenient to study the spatial and seasonal variation by any one orbit. Here two orbits on 11 May near to the epicenter were chosen at local daytime and nighttime respectively, and all of their revisited orbits in a whole year were selected. Based on the similarity between the variation curves, these orbits were divided into several groups: first following the up (in local nighttime) and down-orbits (in local daytime) (Fig. 2), and second by different month and season. The shapes of $\mathrm{O}^{+}$density along the orbits are typical 

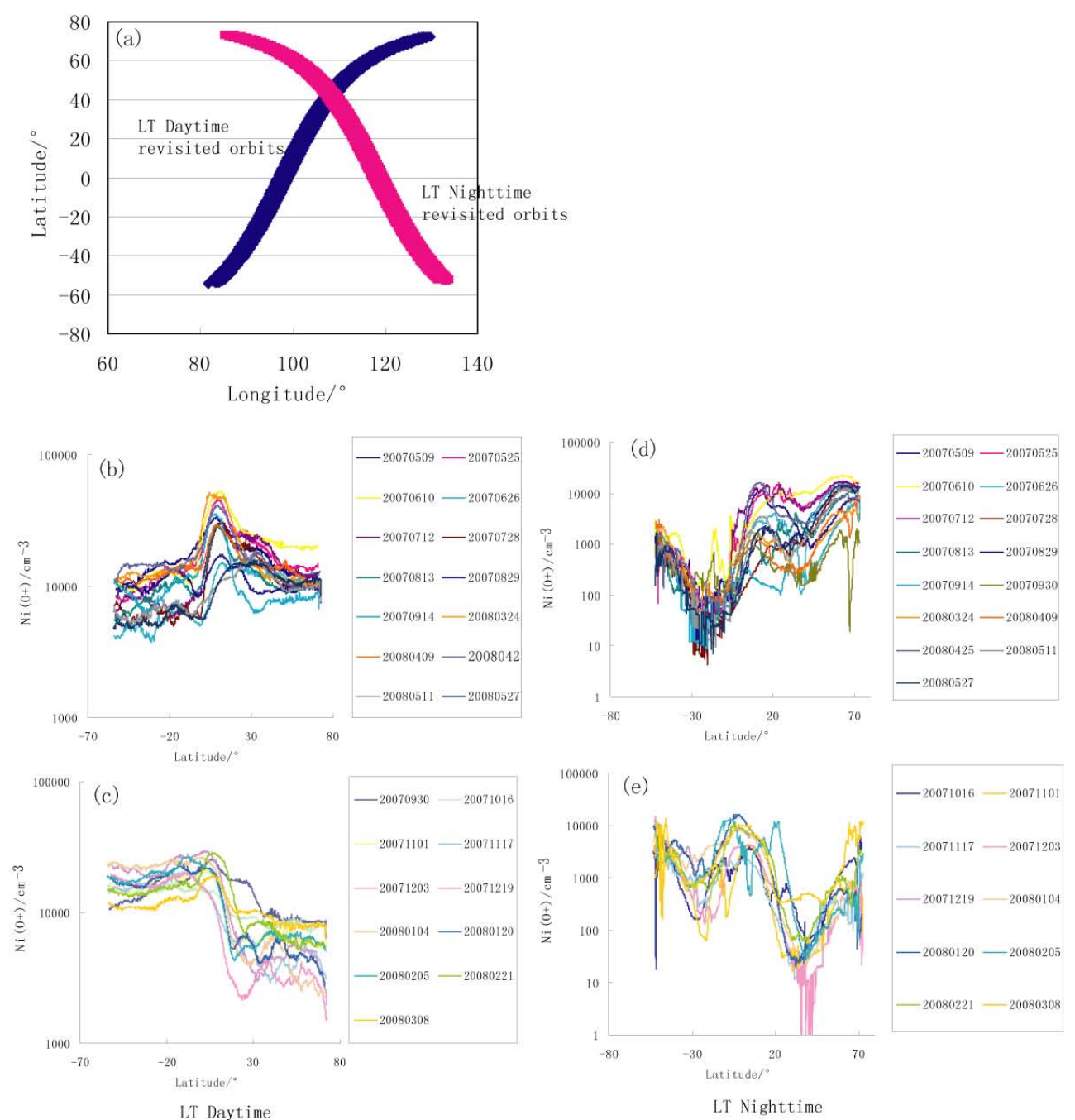

Fig. 2. Seasonal variation at daytime and nighttime of oxygen density by revisited orbits in the studied area((a): revisited orbits in local daytime (red curves) and nighttime(blue curves); (b) $N_{i}\left(\mathrm{O}^{+}\right)$curves of local daytime in summer and autumn seasons; (c) $N_{i}\left(\mathrm{O}^{+}\right)$curves of local daytime in winter and spring seasons; (d) $N_{i}\left(\mathrm{O}^{+}\right)$curves of local nighttime in summer and autumn seasons; (e) $N_{i}\left(\mathrm{O}^{+}\right)$curves of local nighttime in winter and spring seasons).

different in daytime due to the solar activity with those in nighttime. Besides, at daytime, one of season groups is from April to September with single peak area at $0-20^{\circ} \mathrm{N}$, while the other group includes the other months with a flat high $N_{i}\left(\mathrm{O}^{+}\right)$in Southern Hemisphere and a flat lower $N_{i}\left(\mathrm{O}^{+}\right)$in Northern Hemisphere. During winter and spring (from October to March of next year), the $\mathrm{O}^{+}$density in the Southern Hemisphere is always larger than those in the Northern Hemisphere in nighttime. But in summer and autumn, the shapes in nighttime is just reverse with the Southern and Northern Hemisphere. The results demonstrate the significant seasonal variations in $N_{i}\left(\mathrm{O}^{+}\right)$.

\subsection{Data Analysis of the $\mathrm{O}^{+}$density}

Because DEMETER is a nearly sun synchronous satellite, the local time of every orbit passing the equator is designed as the same, being 10:00 at daytime and 22:00 at nighttime. The local time at high latitude with that at equatorial area could vary from 1 to $2 \mathrm{~h}$. To search for anomalous signals recorded in the orbits above the epicenter area and to avoid the effects of the local time on the ionospheric parameters, the data were chosen only in a latitude band between $20^{\circ} \mathrm{N}$ and $40^{\circ} \mathrm{N}$ just around the epicenter. They were detected during the daytime interval 02:00-05:00 UT, i.e. a Beijing time of 10:00-13:00. Within the chosen latitude band, the local time differences are reduced to $10-15 \mathrm{~min}$, and it can be thought that the data were recorded at similar local time. Based on the seasonal analysis, the $\mathrm{O}^{+}$density for the down 

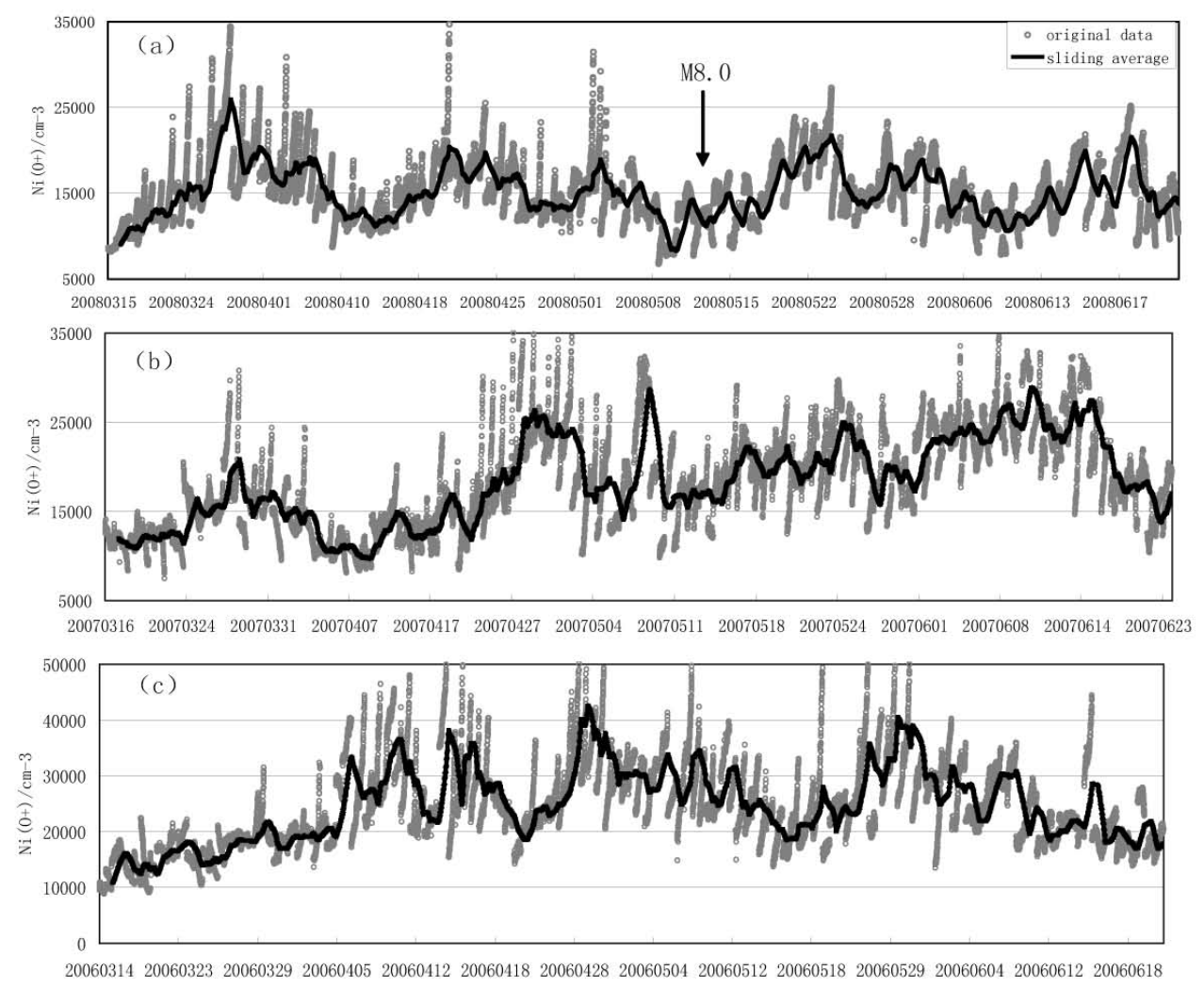

Date/yyyymmdd

Fig. 3. $N_{i}\left(\mathrm{O}^{+}\right)$temporal series during March to June in 2008(a), 2007(b) and 2006(c) respectively (all panels of this figure must be described in the legend).

orbit recorded at local daytime should present a peak region at $0-20^{\circ} \mathrm{N}$ in May. Checking the data 10 days before the Wenchuan earthquake above the studied area, an obvious decrease of $\mathrm{O}^{+}$density was found on 9 May. It is lower than $10000 \mathrm{~cm}^{-3}$, the lowest part during 1st to 12 th May. Is it a seismic precursor related to the earthquake? In order to determine this, the IAP data more than three months was collected around the earthquake occurring time. The $\mathrm{O}^{+}$density in the latitude range $20-40^{\circ} \mathrm{N}$ on those orbits in a distance less than $2000 \mathrm{~km}$ from the epicenter was selected and plotted as a function of time in Fig. 3 during March to June 2008 (Fig. 3). The results clearly show some increasing and decreasing variations in the sliding averaged curve. The data during the same time period and in the same area in 2007 and 2006 was also exhibited in Fig. 3 for comparison. Both of them show similar increase trend in the whole month of May, which may be due to the seasonal solar activity in summer. Although there are some undulations, the lowest values of the $\mathrm{O}^{+}$density in May 2007 and May 2006 were larger than $15000 \mathrm{~cm}^{-3}$. Therefore, combining all these observations during three years, the conclusion can be drawn that the dramatic decrease on 9 May 2008 is unique at this area and during this time period of the year, so it may be correlated to the Wenchuan earthquake.

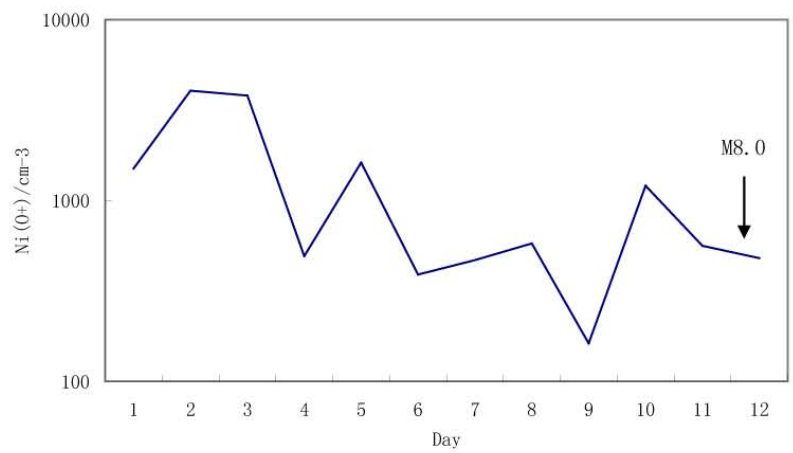

Fig. 4. Daily averaged $N_{i}\left(\mathrm{O}^{+}\right)$on local nighttime during 1 to 12 May 2008.

At the local nighttime, the $\mathrm{O}^{+}$density also shows a small amplitude decreasing variation on 9 May in the studied area, which is consistent with the decreasing anomaly at local daytime. The daily averaged values of $N_{i}\left(\mathrm{O}^{+}\right)$were calculated in local nighttime during 1st to 12th of May in the scale of $20-40^{\circ} \mathrm{N}$ and on the up-orbits within distance of $2000 \mathrm{~km}$ to the epicenter (Fig. 4), which presented the lowest value on 

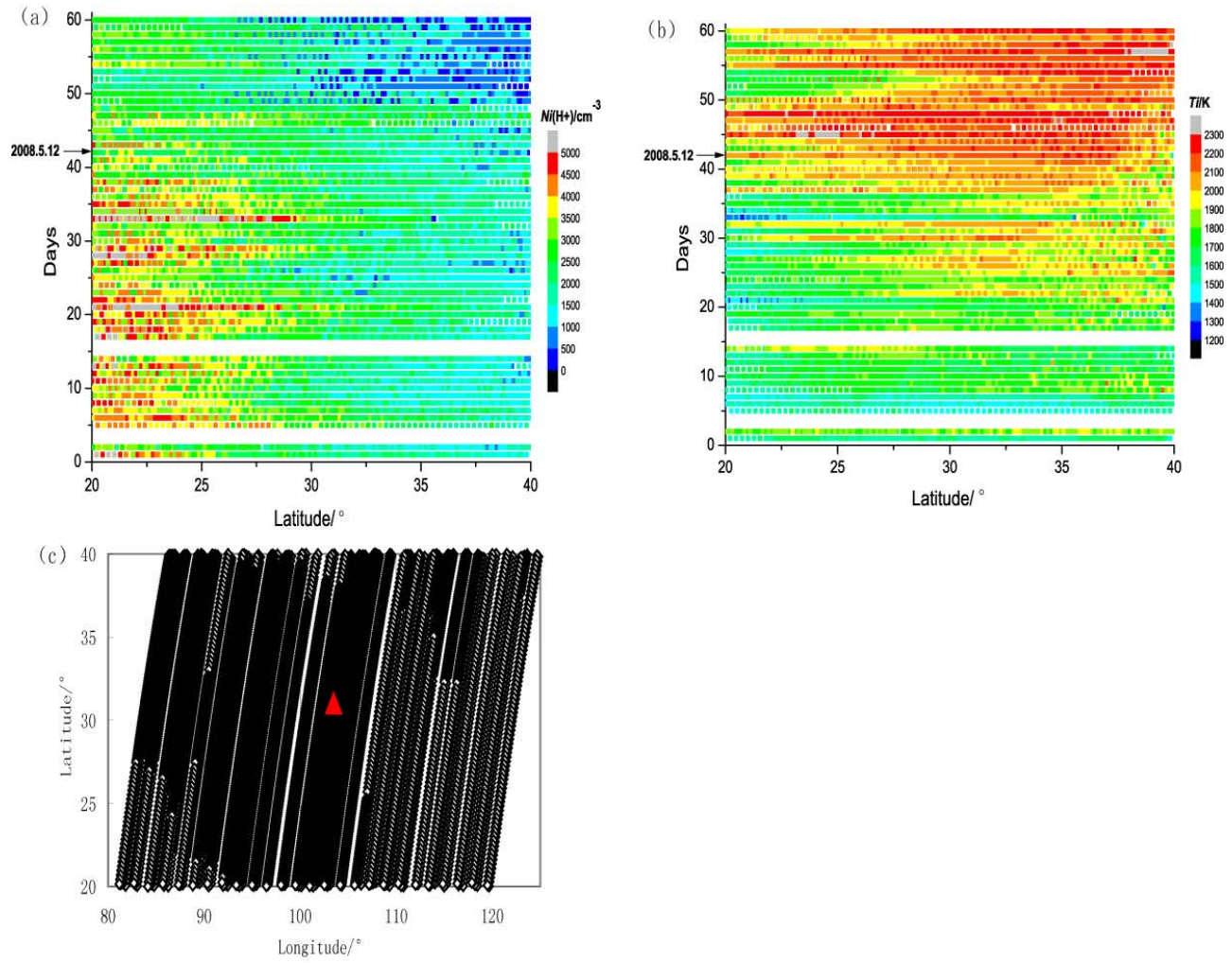

Fig. 5. Images at daytime during 1 April to 30 May of $N_{i}\left(\mathrm{H}^{+}\right)$(a) and $T_{i}$ (b) and the distribution of orbits used above ((c): red triangle is the Wenchuan epicenter).

9 May, 3 days before the Wenchuan earthquake. So $N_{i}\left(\mathrm{O}^{+}\right)$ decreased at the $660 \mathrm{~km}$ altitude in ionosphere whatever in daytime or in nighttime, that means this ionospheric anomalies might last more than $12 \mathrm{~h}$ on 9 May.

Zeng et al. (2009) have shown a plasma anomaly occurring on 5 May, when the $\mathrm{O}^{+}$density presents a quick increase just above the epicenter and they claim that it was the only orbit showing this quick and short variation during the 1 to 12 May. However, after the data in April was checked, at least three similar variations were found. Even some revisited orbits in winter or spring at nighttime showed such fast increase around $30^{\circ} \mathrm{N}$ (see Fig. 2). So, it is difficult to definitely say that such variation is related to the Wenchuan earthquake if there are no other evidences.

\section{Discussion on other parameters}

Due to the common ionization in ionosphere, the density of $\mathrm{H}^{+}$and $\mathrm{He}^{+}$is correlated to the variation of $\mathrm{O}^{+}$. But, the shapes of these two parameters are different with that of $\mathrm{O}^{+}$, especially the density image of $\mathrm{He}^{+}$is much complex so that anomalies could not be distinguished at all. As to the $\mathrm{H}^{+}$ density in local daytime (see Fig. 5a), it showed higher values at the latitude of $20-27^{\circ} \mathrm{N}$ and lower values at $33-40^{\circ} \mathrm{N}$ from 1 April to 17 May. Even in quiet magnetic time, the higher values were always above $3500 \mathrm{~cm}^{-3}$ at the latitude of $20-27^{\circ} \mathrm{N}$. Then from 18 May, the whole $N_{i}\left(\mathrm{H}^{+}\right)$values decreased. The similar variation shape of $\mathrm{H}^{+}$in such a long time could not be recognized as anomalies related to the Wenchuan earthquake, but being much more like seasonal variation.

It is the reverse relative to $N_{i}\left(\mathrm{H}^{+}\right)$for the variation shape of the ion temperature $\left(T_{i}\right)$ recorded at local daytime since 1 April (Fig. 5b). The higher $T_{i}$ is, the smaller $N_{i}\left(\mathrm{H}^{+}\right)$is. $T_{i}$ obviously increased since 21 April at $27-40^{\circ} \mathrm{N}$, and maintained to the earthquake occurrence (see Fig. 5b). The change during 21 April to 3 May might be the result of the magnetic storms. But the increase of $T_{i}$ around 10 May, which was a quiet day, may be related to the earthquake. After the Wenchuan earthquake on 12 May, $T_{i}$ increased above $2100^{\circ} \mathrm{K}$ in most orbits. Checking the variation of the $\mathrm{H}^{+}$ density, it is shown that high $T_{i}$ was always corresponding to low $\mathrm{H}^{+}$density, which coincide with the law of plasma physics. Therefore intensive variations after the earthquake might be included in the effects of seasonal factors.

Ion temperature at night time was also measured by IAP on the DEMETER satellite. After considering the trend variations of other plasma parameters related to seasonal factors in ionosphere, only the fast and short-term variations of $T_{i}$ were analyzed in this paper. The $T_{i}$ data in the latitude range of 


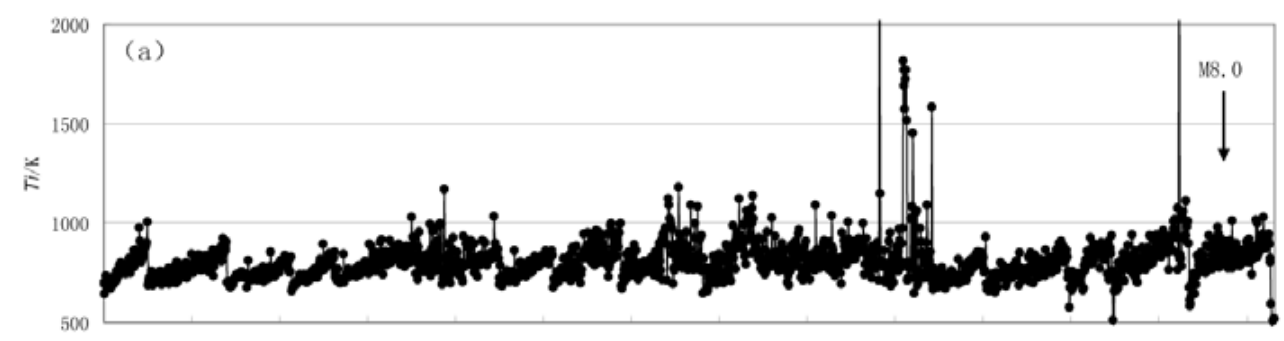

2008050120080501200805022008050320080504200805052008050720080507200805082008050920080510200805112008051120080512

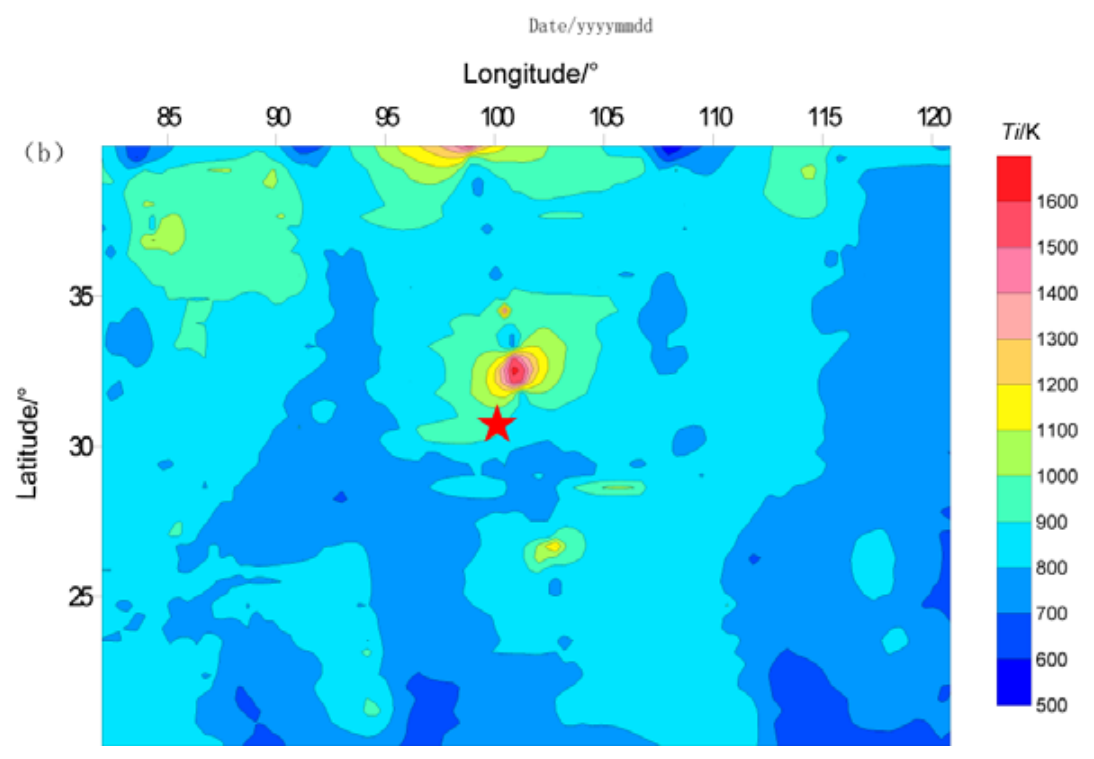

Fig. 6. $T_{i}$ curves at local nighttime during 1 to 12 May (a) and $T_{i}$ contour in 7 to 11 May (b).

$20-40^{\circ} \mathrm{N}$ on the orbits at a distance less than $2000 \mathrm{~km}$ from the epicenter of Wenchuan earthquake were exhibited during 1st to 12 th May in Fig. 6a. It was very clearly seen that $T_{i}$ increased quickly on 9 May with the amplitude exceeding $1500 \mathrm{~K}$ (Fig. 6a) while the normal level below $1000 \mathrm{~K}$. Figure $6 \mathrm{~b}$ gives the $T_{i}$ contour of 5 days before the earthquake in 7 to 10 May using Kriging interpolation method in software Surfer where 5 days' coverage in this area could assure the longitudinal accuracy. The anomalous orbits on 9 May are the nearest orbit to the epicenter, while $T_{i}$ on other orbits varied smoothly on those days (Fig. 6b). So it can be concluded that $T_{i}$ on 9 May was a regional increase at nighttime, especially in the northeastern region of the Wenchuan earthquake.

\section{Conclusions}

Based on $\mathrm{O}^{+}$number density data recorded by the DEMETER satellite at the altitude of $660 \mathrm{~km}$, the phenomenon of seasonal variations of oxygen density in the studied area were summed up. At different seasons, the shapes of the $\mathrm{O}^{+}$density curves are obviously different.
By comparison of the $\mathrm{O}^{+}$density from March to June in 2008, 2007 and 2006, the results reflect that, the decreasing $N_{i}\left(\mathrm{O}^{+}\right)$on 9 May 2008 at daytime in ionosphere especially may be related to the Wenchuan 8.0 earthquake. Also on the same day, the nighttime $\mathrm{O}^{+}$density also decreased with small amplitude. In addition, the ion temperature detected by IAP was found with fast and short-term and regional anomalies at nighttime on 9 May. All these demonstrate the seismo ionospheric anomalies prior to the Wenchuan earthquake.

Zhao et al. (2008a, b) obtained TEC anomalies based on GPS data on the ground of four stations in China and other GPS stations in Japan. Their results showed increasing TEC at low and mid latitude in the afternoon of 9 May. The results of Liu et al. (2009) about the GPS TEC anomaly before Wenchuan earthquake showed that, the GPS TEC above the epicenter anomalously decreased in the afternoon of day 6-4 and the late evening period of day 3 before the earthquake, but enhances in the afternoon of day 3 before the earthquake. In this paper, whatever at local daytime or nighttime the ion density of oxygen showed decrease variations, and the ion temperature showed some perturbations above the epicentral area. Tracing it to its cause, the time of satellite passing over the earthquake was in the morning at local 10:00 to 
11:00 a.m. and in the nighttime of local 09:00-10:00 p.m according to the attitude designed for the satellite, so it can not observe the variation in the afternoon time. But the daytime and nighttime decrease of the $\mathrm{O}^{+}$density in this paper well coincides with the results of Liu et al. (2009), which enhances the reliability of the ionospheric anomalies related to the Wenchuan earthquake.

Besides the results in this paper, some anomalies have been found (He et al., 2009; Zeng et al., 2009) in VLF transmitter signals and other parameters. As for the mechanism of these anomalous phenomena, the first is that the fracture of faults in epicentral area could produce strong vertical electric field, penetrating into plasmasphere from seismic source, forming VLF duct in the plasmasphere, and then leading to precipitation of energetic particles into lower atmosphere and increase of electron density in ionospheric D-region (Pulinets and Boyarchuk, 2004). Kim and Hegai (1999) and Kim et al. (2002) had calculated and proved it in theory about the penetration of the electrostatic field of seismic origin into the lower ionosphere. Shklyar and Truhlik (1998) analyzed the ion balance within the magnetospheric tube affected by the electric field of seismic origin perpendicular to the geomagnetic field line. They demonstrated the high sensitivity of the light ions to the changes in the background ionosphere on which the modified magnetic tube is loaned, especially in the transitions region where concentration of the light and heavy ions is comparable. Based on this, the decrease of oxygen density and increase of $T_{i}$ at the altitude of satellite may indicate the increase of ions at lower ionosphere that had been found in other study (Zhao et al., 2008; Liu et al., 2009), and all the perturbations in ionosphere may be resulted from the penetration of electric field. The second mechanism could be related to the chemical material emitted from micro-fractures in earthquake region, which leads to AGW in atmosphere, then disturbing the lower ionosphere and result in the changes of electron density and ion density, and other parameters in other layers of the ionosphere (Pulinets and Boyarchuk, 2004). Unfortunately, the stations observing the water radon in southwestern China did not detect any imminent anomalies, so the second mechanism can not be supported for this case. It is known that the coupling mechanism among lithosphere-atmosphere-ionosphere is complex, and multi kinds of observation at ground, atmosphere and ionosphere, even in magnetosphere should be strengthened in future for further understanding the coupling mechanism from seismic source to ionosphere.

Acknowledgements. The authors thank CNES which gave us the opportunity to be guest investigators of the DEMETER mission. They thank M. Parrot, J. J. Berthelier and Jean-Yves Brochot for their help in data collection and handling. This paper is funded by National Science and Technology Program (2008BAC35B01) and Basic Research project of Institute of Earthquake Science, CEA.

Edited by: M. E. Contadakis

Reviewed by: two anonymous referees

\section{References}

Bhattacharya, S., Sarkar, A., Gwal, A. K., and Parrot, M.: Observation of ULF/ELF anomalies detected by DEMETER satellite prior to earthquakes, Indian Jounal of Radio \& Space Physics, 36, 103-113, 2007.

Bošková, J., Šmilauer, J., and Tíska, P.: Is the ion composition of the outer ionosphere related to seismic activity?, J. Atmos. Solar Terr. Phys., 55, 1689-1695, 1993.

Bošková, J., Šmilauer, J., Tíska, P., and Kudela, K.: Anomalous behavior of plasma parameters as observed by the intercosmos 24 satellite prior to the Iranian earthquake of 20 June 1990, Studia Geoph. Et Geod., 38, 213-220, 1994.

Cussac, T., Clair, M. A., Ultre-Guerard, P., et al.: The Demeter microsatellite and ground segment, Planet. Space Sci., 54, 413427, 2006.

He, Y. F., Yang, D. M., Chen, H. R., et al.: SNR changes of VLF radio signals detected onboard the DEMETER satellite and their possible relationship to the Wenchuan earthquake, Sci. China Ser. D, 52, doi:10.1007/s11430-009-0064-5, 2009.

Kim, V. P. and Hegai, V. V.: A possible presage of strong earthquakes in the nighttime mid latitude associated with earthquakes, in: Atmospheric and Ionoshperic Electromagnetic Phenomena Associated with Earthquakes, edited by: Hayakawa, M., Terra Scientific Publishing Company, Tokyo, 619-627, 1999.

Kim, V. P., Pulinets, S. A., and Hegai, V. V.: The theoretical model of the possible changes in the night-time midlatitude D-region of the ionosphere over the zone of strong earthquake preparation, Radiophys. Quantum Radiophys., 45, 289-296, 2002.

Lagoutte, D., Brochot, J. Y., de Carvalho, D., et al.: The DEMETER satellite science mission centre, Planet. Space Sci., 54, 428-440, 2006.

Liu, J. Y., Chen, Y. I., Chen, C. H., et al.: Seismoionoshperic GPS total electron content anomalies observed before the 12 May 2008 Mw7.9 Wenchuan earthquake, J. Geophys. Res., 114, A04320, doi:10.1029/2008JA013698, 2009.

Parrot, M., Berthelier, J. J., Lebreton, J. P., et al.: Examples of unusual ionospheric observations made by the DEMETER satellite over seismic regions, Phys. Chem. Earth, 31, 486-495, 2006.

Pulinets, S. A. and Boyarchuk, K.: Ionospheric precursors of earthquakes, Springer, Berlin, Germany, 75-169, 2004.

Pulinets, S. A., legen'ka, A. D., Gaivoronskaya, T. V., and Depuev, V. K.: Main phenomenological features of ionospheric precursors of strong earthquakes, J. Atmos. Sol.-Terr. Phy., 65, 13371347, 2003.

Sarkar, S., Gwal, A. K., and Parrot, M.: Ionospheric variations observed by the DEMETER satellite in the mid-latitude region during strong earthquakes, J. Atmos. Sol.-Terr. Phy., 69, 1524-1540, 2007.

Shklyar, D. R. and Truhlik, V.: On the modification of light ion concentration profiles above seismicity active regions: a qualitative consideration, J. Atmos. Sol.-Terr. Phy., 60, 1025-1033, 1998.

Zeng, Z. C., Zhang, B., Fang, G. Y., et al.: The analysis of ionospheric variations before the Wenchuan earthquake with DEMETER data, Chinese J. Geophys., 52, 1, 11-19, 2009.

Zhao, B., Wan, W., Wang, M., et al.: Recent advances on the ionospheric precursors of earthquakes and ionospheric variation prior to Wenchuan earthquake, Sci \& Technology Rev., 11, 30-34, 2008a (in Chinese with English Abstract). 
Zhao, B., Yu, T., Wang, M., et al.: Is an unusual large enhancement of ionospheric electron density linked with the 2008 great Wenchuan earthquake?, J. Geophys. Res., 113, A11304, doi:10.1029/2008JA013613, 2008b.
Zhu, R., Yang, D. M., Jing, F., Yang, J. Y., and Ouyang, X. Y.: Ionospheric perturbations before pu'er earthquake observed on DEMETER satellite, Acta Seismologica Sinica, 21(1), 77-81, 2008. 